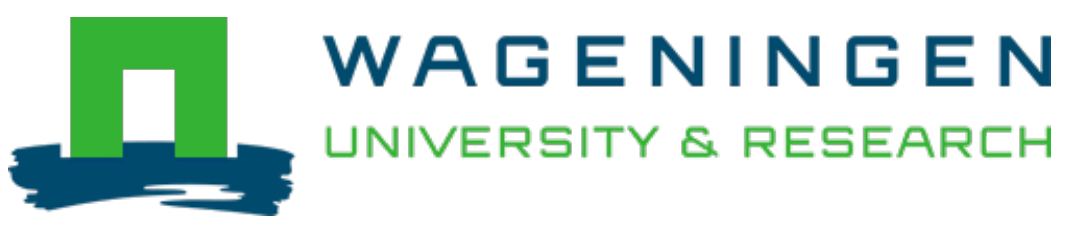

\title{
Cover crops promote primary crop yield in China : A meta-regression of factors affecting yield gain
}

\author{
Field Crops Research \\ Fan, Fan; Werf, Wopke; Makowski, David; Ram Lamichhane, Jay; Huang, Wenfeng et al \\ https://doi.org/10.1016/j.fcr.2021.108237
}

This publication is made publicly available in the institutional repository of Wageningen University and Research, under the terms of article $25 \mathrm{fa}$ of the Dutch Copyright Act, also known as the Amendment Taverne. This has been done with explicit consent by the author.

Article 25 fa states that the author of a short scientific work funded either wholly or partially by Dutch public funds is entitled to make that work publicly available for no consideration following a reasonable period of time after the work was first published, provided that clear reference is made to the source of the first publication of the work.

This publication is distributed under The Association of Universities in the Netherlands (VSNU) 'Article $25 \mathrm{fa}$ implementation' project. In this project research outputs of researchers employed by Dutch Universities that comply with the legal requirements of Article $25 \mathrm{fa}$ of the Dutch Copyright Act are distributed online and free of cost or other barriers in institutional repositories. Research outputs are distributed six months after their first online publication in the original published version and with proper attribution to the source of the original publication.

You are permitted to download and use the publication for personal purposes. All rights remain with the author(s) and / or copyright owner(s) of this work. Any use of the publication or parts of it other than authorised under article $25 \mathrm{fa}$ of the Dutch Copyright act is prohibited. Wageningen University \& Research and the author(s) of this publication shall not be held responsible or liable for any damages resulting from your (re)use of this publication.

For questions regarding the public availability of this publication please contact openscience.library@wur.nl 


\title{
Cover crops promote primary crop yield in China: A meta-regression of factors affecting yield gain
}

\author{
Fan Fan ${ }^{\mathrm{a}}$, Wopke van der Werf ${ }^{\mathrm{b}}$, David Makowski ${ }^{\mathrm{c}}$, Jay Ram Lamichhane ${ }^{\mathrm{d}}$, Wenfeng Huang ${ }^{\mathrm{a}}$, \\ Chunjie $\mathrm{Li}^{\mathrm{a}}$, Chaochun Zhang ${ }^{\mathrm{a}}$, Wen-Feng Cong ${ }^{\mathrm{a}}{ }^{*}$, Fusuo Zhang ${ }^{\mathrm{a}, *}$ \\ ${ }^{\text {a }}$ College of Resources and Environmental Science, National Academy of Agriculture Green Development, China Agricultural University, 100193, Beijing, China \\ ${ }^{\mathrm{b}}$ Centre for Crop Systems Analysis, Wageningen University, $6700 \mathrm{AK}$, Wageningen, the Netherlands \\ ${ }^{\mathrm{c}}$ Université Paris-Saclay, AgroParisTech, INRAE, UMR 518 MIA, 75231, Paris, France \\ ${ }^{\mathrm{d}}$ French National Institute for Agriculture, Food, and Environment (INRAE), Université Fédérale de Toulouse, UMR AGIR, F-31326, Castanet-Tolosan Cedex, France
}

\section{A R T I C L E I N F O}

\section{Keywords:}

Cover crop

Cropping systems

Yield

Meta-regression

China

\begin{abstract}
A B S T R A C T
Inclusion of cover crops (CCs) in cropping systems can improve soil quality, reduce agricultural inputs, and improve environmental sustainability. While CCs have been widely promoted in China in recent years, a quantitative assessment of CC effect on crop yield across China is lacking. There is also no overarching analysis on factors explaining variation in yield effects. Here, we carried out a meta-analysis to evaluate the effects of CCs on subsequent primary crop yield in China, based on 53 published studies reporting 442 yield ratios with and without CCs. We found that CCs increased subsequent primary crop yields by $9.7 \%$ on average when compared with fallow across China. The effects of CC varied with different factors related to climatic zone, field management and soil properties. CC type (legume or not), CC season (growing in winter or summer) and nitrogen input were factors substantially influencing primary crop yield. We identified high yield benefits in subtropical rice systems with winter CCs $(12.9 \pm 3.9 \%)$ but no significant yield benefits in temperate wheat systems with summer CCs $(1.9 \pm 6.6 \%)$. Within subtropical rice systems, both legume and non-legume CCs were tested widely, and the effects of legume CCs $(14.6 \pm 4.0 \%)$ on primary crop yield were greater than those of nonlegume CCs $(7.9 \pm 3.7 \%)$. The yield benefits of CCs decreased with increasing fertilizer inputs. These results may be used for developing policy recommendations to improve primary crop yield by integrating targeted CCs associated with nitrogen management into cropping systems in China.
\end{abstract}

\section{Introduction}

Modern agriculture highly relies on the use of chemical fertilizers and pesticides that ensure high crop productivity (Bennett et al., 2012; Zhao et al., 2020). This production model, however, led to serious environmental problems, including soil acidification (Guo et al., 2010), ground water pollution (Alexander et al., 2008; Blesh and Drinkwater, 2013), air pollution (Liu et al., 2013) and biodiversity loss (Tilman et al., 2002). Designing and testing of new and alternative agronomic solutions to the conventional ones have thus become an urgent need to improve the sustainability of the current cropping systems while maintaining or increasing the agricultural productivity.

Cover crops (CCs) are generally grown during the fallow period between the harvest of the previous and sowing of the subsequent primary crops. CCs serve many purposes, e.g. preventing $\mathrm{N}$ leaching, building soil organic matter, $\mathrm{N}$ fixation from the atmosphere, soil health improvement, and weed control. CC has been recommended as a potential solution to replace external inputs and mitigate negative environmental impacts of agriculture (Kaye and Quemada, 2017; Bergtold et al., 2019).

In Europe and North America, much research has been done on the use of CCs to alleviate environmental impacts of agriculture (Poeplau and Don, 2015). Repullo-Ruibérriz de Torres et al. (2018) reported that CCs are a useful agro-ecological tool that can protect the soil from erosion. Quemada et al. (2013) and Thapa et al. (2018) stated that replacing a fallow with CCs could reduce $\mathrm{N}$ leaching by $50 \%$. Jian et al. (2020a) reported that worldwide use of CCs could increase global soil organic carbon by $15.5 \%$. Vogelweith and Thiéry (2017) found that agricultural rotations with CCs could enhance natural enemy populations and reduce pest arthropods in vineyards. Larkin et al. (2010)

\footnotetext{
* Corresponding author at: No. 2 Yuanmingyuan West Road, 100193, Beijing, China.

E-mail addresses: wenfeng.cong@cau.edu.cn (W.-F. Cong), zhangfs@cau.edu.cn (F. Zhang).
} 
showed that the addition of CCs had significant effects on soil microbial characteristics that can provide improved control of soil-borne diseases. Finally, Toler et al. (2019) found that CCs can suppress weeds and pests in cotton.

Ensuring food security by pursuing high crop production has always been the primary goal of agricultural development in China, because of high Chinese population density and the small arable land area per capita (MARA, 2015). The main purpose of Chinese farmers growing CCs is therefore to improve the main crop yield. New farming agricultural technologies, such as the use of synthetic fertilizers, breeding, and farm machinery, have contributed to the large increase in crop yield observed in China since the 1980s (Edgerton, 2009). However, increasing exogenous fertilizers to achieve higher crop production is no longer a viable option in China. Indiscriminate use of synthetic fertilizers, especially nitrogen, has been regarded as the major contributor to agricultural pollution in China (Gong et al., 2011), that resulted in environmental concerns, such as soil acidification (Guo et al., 2010), ground water (Alexander et al., 2008; Blesh and Drinkwater, 2013) and air pollution (Liu et al., 2013).

In 2015, the Chinese central government imposed the "Zero-Growth Action on fertilizer" for reducing systematic overuse of fertilizers (MARA, 2015). To ensure an effective supply of agricultural products and promote sustainable agricultural development, the application of organic fertilizers and green manures (i.e. CCs), has been considered as an efficient farming technique to replace synthetic fertilizers while improving the soil quality. To test the potential of CCs, China has established the Green Manure National Experiment Network since the 1970s (Cao et al., 2017). Recently, many scientific projects have been funded to conduct CCs studies, and the Chinese central government launched the Green Manure Planting Program (GMPP) to reduce soil degradation and stabilize food production by taking advantage of eco-functions of green manure crops. So far, the number of farmers adopting the GMPP has increased over the years leading to a continuous expansion of the GMPP area (Li et al., 2020b). The adoption of CCs has been considered as one of the most effective agricultural diversification practices to promote Chinese sustainable agricultural development ( $\mathrm{Li}$ et al., 2020b).

It is not well known how CCs influence the primary crop yield in China. Most Chinese studies report that CCs had positive effect on primary crop yield in the arable land, however, no quantitative synthesis analysis of this information has been reported. Meta-analysis is the quantitative and scientific synthesis that combines the results of multiple studies on a common subject to draw general conclusions (Makowski et al., 2019). Several meta-analyses have been conducted to analyse the potential of CCs to change the yield of subsequent cash crops under different conditions. By compiling data from 269 studies globally, Jian et al. (2020b) reported 4\% increases in crop yield by applying CCs. However, Abdalla et al. (2019) demonstrated that CCs induced a 4\% reduction in grain yield of the subsequent crop based on an analysis of 106 studies at a global scale. Osipitan et al. (2018) found that the use of CCs for early season weed suppression did not affect main crop grain yield when compared with fallow, based on 46 relevant studies across the globe. Marcillo and Miguez (2017) stated that in the United States and Canada, the effects of CCs on subsequent maize yield varied according to farming practices and soil properties. It is becoming imperative to make a quantitative synthesis of the available information from China to allow policy-makers and other stake-holders to develop future guidance for agricultural policies and crop system management. Therefore, the overall objective of this study was to use meta-analysis to quantitatively synthesize the effects of CCs on subsequent crop yield in China. More specific objectives of this study were to (1) estimate crop yields comparing systems with and without CCs; (2) analyse the relative important variables contributing to the effects of CCs on crop yield.

\section{Materials and methods}

\subsection{Data collection}

Data used in this study were extracted from peer-reviewed papers that were identified using searches on the Web of Science (http://apps. webofknowledge.com/) and the China National Knowledge Infrastructure (CNKI, http://www.cnki.net/). The searches were last updated on June 30, 2020. We used the terms 'cover crop', or 'catch crop', or 'green manure' and 'China' in the topic field in both databases to identify potentially relevant publications. The identified publications were screened for relevance. Detailed searching and screening procedures are presented in Fig. S1 using the PRISMA flow diagram. Following these criteria, the final dataset included 442 observations.

Data were directly extracted from tables and figures using the software GetData Graph Digitizer (version 2.22) (http://getdata-graph-digit izer.com/). For each study and experiment (unique combinations of site and year), the geographic locations, initial soil properties, and primary crop fertilizers ( $\mathrm{N}, \mathrm{P}$ and $\mathrm{K}$ ) application rates were collected from the articles. For each treatment, the pairwise yield of the primary crops with and without CC was recorded. For the CC treatment, the CC type (Legume/non-legume) and CC season (growing in winter or summer CC) were also recorded into the database (Table 1 ).

\subsection{Variables and groupings}

\subsubsection{Response variable}

Response ratio (RR) was used to assess the effect of CCs on primary crop yield in comparison with fallow. The natural logarithm (LnR) of the response ratio was used as response metric (effect size of this meta-

Table 1

Variables extracted from publications.

\begin{tabular}{|c|c|c|}
\hline Variable & Definition & $\begin{array}{l}\text { Data type/ } \\
\text { Unit }\end{array}$ \\
\hline Title & Title of publication & Text \\
\hline Authors & Authors of publication & Text \\
\hline Journal name & The name of the journal & Text \\
\hline Year of publication & The publication year & Text \\
\hline Latitude & Latitude of the experimental site & $\begin{array}{l}\text { Decimal } \\
\text { degree }\end{array}$ \\
\hline longitude & Longitude of the experimental site & $\begin{array}{l}\text { Decimal } \\
\text { degree }\end{array}$ \\
\hline MAP & $\begin{array}{l}\text { Mean annual precipitation at the } \\
\text { experimental site }\end{array}$ & $\mathrm{mm} /$ year \\
\hline MAT & $\begin{array}{l}\text { Mean annual temperature at the } \\
\text { experimental site }\end{array}$ & ${ }^{\circ} \mathrm{C}$ \\
\hline Soil pH & Initial soil $\mathrm{pH}$ of the experimental sites & None \\
\hline $\mathrm{N}$ input & $\begin{array}{l}\text { Amount of } \mathrm{N} \text { fertilizer applied to primary } \\
\text { crops per unit area of the whole field }\end{array}$ & $\mathrm{kg} / \mathrm{ha}$ \\
\hline $\mathrm{P}$ input & $\begin{array}{l}\text { Amount of } \mathrm{P} \text { fertilizer applied to primary } \\
\text { crops per unit area of the whole field }\end{array}$ & $\mathrm{kg} / \mathrm{ha}$ \\
\hline $\mathrm{K}$ input & $\begin{array}{l}\text { Amount of } \mathrm{K} \text { fertilizer applied to primary } \\
\text { crops per unit area of the whole field }\end{array}$ & $\mathrm{kg} / \mathrm{ha}$ \\
\hline Climatic zone & $\begin{array}{l}\text { Climatic zone of the experimental site } \\
\text { (subtropical or temperate) }\end{array}$ & Categorical \\
\hline Primary crop species & $\begin{array}{l}\text { Primary crops species (including Rice: } \\
\text { first season rice, Rice*: second season } \\
\text { rice, maize, wheat and others) }\end{array}$ & Categorical \\
\hline CC type & $\begin{array}{l}\text { Whether the cover crop (CC) species is } \\
\text { legume or non-legume }\end{array}$ & Categorical \\
\hline CC season & $\begin{array}{l}\text { Whether the CC is grown in winter } \\
\text { (winter CCs: planted in October and } \\
\text { terminated in March) or summer } \\
\text { (summer CCs: planted in June, July or } \\
\text { August and harvest before October) }\end{array}$ & Categorical \\
\hline $\begin{array}{l}\text { Combinations of CC } \\
\text { type and CC season }\end{array}$ & $\begin{array}{l}\text { (Winter, Summer) } \times \text { (Legume, Non- } \\
\text { legume): Winter legume, Winter non- } \\
\text { legume, Summer legume (Fig.1) }\end{array}$ & Categorical \\
\hline Yield & $\begin{array}{l}\text { Yield of primary crops with or without } \\
\text { CC }\end{array}$ & t/ha \\
\hline
\end{tabular}


analysis):

$\operatorname{LnR}=\ln \left(\right.$ Yield $_{\mathrm{C}} /$ Yield $\left._{\mathrm{F}}\right)$

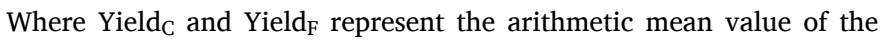
primary crop yield in the CC treatment and control (fallow) treatments, respectively. LnR is commonly used in meta-analysis to correct the differences in scale and size of response variables between studies (Hedges et al., 1999; Koricheva et al., 2013) and is considered a robust metric for making statistical comparisons (Seufert et al., 2012). The overall mean effect size $\overline{\operatorname{LnR}}$ and its $95 \%$ confidence interval was estimated while accounting for random study effects using mixed effects models (Makowski et al., 2019), as explained below (Table 2). The mean effect size was exponentially transformed back to a percentage yield change, calculated as $[\exp (\overline{\operatorname{LnR}})-1] \times 100 \%$.

\subsubsection{Explanatory variables}

The effects of CCs on the primary crop yield are likely to vary in response to climate, soil properties, crop species, and management (Sileshi et al., 2008; Alvarez et al., 2017; Marcillo and Miguez, 2017; Toler et al., 2019). These factors were considered as explanatory variables to explain variation in $\ln R$. Several categorical moderator variables were defined (Table 1). The climatic zone of each site was classified as subtropical or temperate zone, based on Li (1999). Primary annual field crop species were classified in five categories, viz. Rice: first season rice (where rice was planted following CC, growth period normally from March to late June, could be early rice and middle rice), Rice*: second season rice (where rice was planted after harvesting first season rice, growth period from June to October, only for late rice), wheat, maize, and others (including cotton, melon and tobacco). Rice was planted only once in a year (one season rice) across some areas while the crop was planted twice per year across other areas (two season rice). In the latter case, the yields of both first and second season rice were recorded. We distinguished first season and second season rice to identify the time effectiveness of CCs. CC type was categorized as legume CCs and non-legume CCs, while CC season was classified as winter CC and summer CC. Winter CCs were normally planted in October and terminated in March, whereas summer CCs were normally planted in late June, July or August and terminated in late September or October. Furthermore, CC type combined with CC season were defined as three main groups: winter legume, winter non-legume and summer legume based on the data structure (Figs. 1 and S2 only 3 observations of summer non-legume). Mean effect sizes for the above categories were estimated using mixed effects models with categorical co-variables
(Table 2).

\subsection{Statistical analysis}

All analyses were conducted in the $\mathrm{R}$ statistical software version 4.0.2 ( $\mathrm{R}$ Core Team, 2020). Linear regression with mixed-effects model (function lme in nlme package; Pinheiro et al. (2009)) was used to estimate the effect size and the $95 \%$ confidence interval (CI) (Table 2). If the $95 \%$ CI of LnR did not include zero, CCs treatments were considered to represent a significant increase $(>0)$ or decrease $(<0)$ when compared with the control $(P<0.05)$. Publications and experiments within publication were treated as random effects to account for differences between the publications and between experiments (sites $x$ years) (Makowski et al., 2019). The R functions AIC() (Calculating Akaike's information criterion) and anova() (Analysis of Variance) were used to identify the best random effects structure and model selection. Significance of differences between levels of categorical explanatory variables were assessed using ANOVA. Because only 49 standard deviations or standard errors were recorded out of a total of 442 observations, an unweighted analysis of effect size was conducted. Unweighted analyses can provide a valid and unbiased evaluation (McDaniel et al., 2014) and have been commonly used in agriculture and ecology (Yu et al., 2015; Wang et al., 2017; Martin-Guay et al., 2018; Li et al., 2020a). A funnel plot relating effect sizes to sample sizes was used to determine whether there was evidence of publication bias (Philibert et al., 2012). Study size was defined as the total number of replicates over all the records per study (Yu et al., 2015). The best models in this study are presented in Table 2. Most analyses included one or two explanatory variables. All cases reporting the variables required for analyzing a specific factor or interaction were included in the analysis. Therefore, analyses for different factors are based on potentially different subsets of the data (Table 2).

We conducted a principal component analysis (PCA) and correlation analysis to assess collinearity between predictors (Climatic zone, CC type, CC season, Soil pH, Crop species, N, P and K inputs). The PCA analysis could only be done for complete cases, and the subset for PCA included 319 observation records from 30 studies. PCA was performed using the "vegan" package (Oksanen et al., 2019) in R. The correlation between LnR and above variables was conducted using the "corrplot" package (Wei and Simko, 2017).

To assess the relative weight of predictors, we conducted multiple linear regression with mixed models, followed by model averaging using the R package "MuMin" (Barton, 2009). "MuMin" creates a set of models

\section{Table 2}

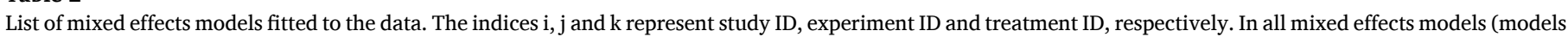

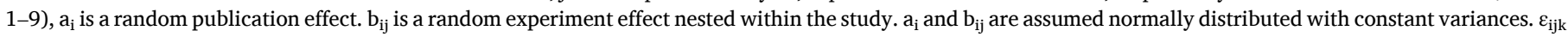
is a residual random error assumed normally distributed with constant variance. The variance terms $\mathrm{a}_{\mathrm{i}}$, $\mathrm{b}_{\mathrm{ij}}$ and $\varepsilon_{\mathrm{ijk}}$ are all assumed independent.

\begin{tabular}{|c|c|c|c|}
\hline Model & Explanatory variables & Equations & Data \\
\hline 1 & & $\operatorname{LnR}_{\mathrm{ijk}}=\beta_{0}+\mathrm{a}_{\mathrm{i}}+\mathrm{b}_{\mathrm{ij}}+\varepsilon_{\mathrm{ijk}}$ & All data \\
\hline 2 & $\begin{array}{l}\mathrm{pH}, \mathrm{CC} \text { type, CC Season, Climatic } \\
\text { zone, } \mathrm{N} \text { inputs, } \mathrm{P} \text { inputs, } \mathrm{K} \text { inputs, } \\
\text { Crop species }\end{array}$ & $\begin{array}{l}\operatorname{LnR}_{i j k}=\beta 0+\beta_{1}{ }^{*} \mathrm{pH}_{\mathrm{ijk}}+\beta_{2}{ }^{*} \text { ClimaticZone }_{\mathrm{ijk}}+\beta_{3}{ }^{*} \text { CCtype }_{\mathrm{ijk}} \\
+\beta_{4}{ }^{*}{ }{ } \text { Cseason }_{\mathrm{ijk}}+\beta_{5}{ }^{*} \mathrm{~N}_{\mathrm{ijk}}+\beta_{6}{ }^{*} \mathrm{P}_{\mathrm{ijk}}+\beta_{7}{ }^{*} \mathrm{~K}_{\mathrm{ijk}}+\beta_{8}{ }^{*} \text { Crop-species }_{\mathrm{ijk}}+\mathrm{a}_{\mathrm{i}}+\mathrm{b}_{\mathrm{ij}}+\varepsilon_{\mathrm{ijk}}\end{array}$ & $\begin{array}{l}\text { Only for records with full information (no missing } \\
\text { data) on soil } \mathrm{pH} \text {, Climatic zone, CC types, CC season, } \\
\mathrm{N} \text { input, } \mathrm{P} \text { input, K input and Crop species }\end{array}$ \\
\hline 3 & Crop-species, winter legume & $\operatorname{LnR}_{\mathrm{ijk}}=\beta_{\text {winter-legume }}\left(\right.$ Crop-species $\left._{\mathrm{ijk}}\right)+\mathrm{a}_{\mathrm{i}}+\mathrm{b}_{\mathrm{ij}}+\varepsilon_{\mathrm{ijk}}$ & Only for legume CCs grown in winter \\
\hline 4 & Crop-species, winter non-legume & $\operatorname{LnR}_{\mathrm{ijk}}=\beta_{\text {winter-nonlegume }}\left(\right.$ Crop-species $\left.\mathrm{ijk}_{\mathrm{jk}}\right)+\mathrm{a}_{\mathrm{i}}+\mathrm{b}_{\mathrm{ij}}+\varepsilon_{\mathrm{ijk}}$ & Only for non-legume CCs grown in winter \\
\hline 5 & Crop-species, Summer legume & $\operatorname{LnR}_{\mathrm{ijk}}=\beta_{\text {Summer-legume }}\left(\right.$ Crop-species $\left._{\mathrm{ijk}}\right)+\mathrm{a}_{\mathrm{i}}+\mathrm{b}_{\mathrm{ij}}+\varepsilon_{\mathrm{ijk}}$ & Only for legume CCs grown in summer \\
\hline 6 & $\mathrm{~N}$ input, Combinations & $\operatorname{LnR}_{\mathrm{ijk}}=\beta_{\mathrm{N}}+\beta_{1}{ }^{*} \mathrm{~N}_{\mathrm{ijk}}+\beta_{2} *$ Combinations $_{\mathrm{ijk}}+\mathrm{a}_{\mathrm{i}}+\mathrm{b}_{\mathrm{ij}}+\varepsilon_{\mathrm{ijk}}$ & $\begin{array}{l}\text { Records with information on } \mathrm{N} \text { concerning legume } \\
\mathrm{CC} \text { grown in winter, non-legume CCs grown in } \\
\text { winter, and legume CC grown in summer }\end{array}$ \\
\hline 7 & $\mathrm{P}$ input, Combinations & LnR $_{\mathrm{ijk}}=\beta_{\mathrm{P}}+\beta_{1} * \mathrm{P}_{\mathrm{ijk}}+\beta_{2}{ }^{*}$ Combinations $_{\mathrm{ijk}}+\mathrm{a}_{\mathrm{i}}+\mathrm{b}_{\mathrm{ij}}+\varepsilon_{\mathrm{ijk}}$ & $\begin{array}{l}\text { Records with information on P concerning legume } \\
\text { CCs grown in winter, non-legume CCs grown in } \\
\text { winter, and legume CCs grown in summer }\end{array}$ \\
\hline 8 & $\mathrm{~K}$ input, Combinations & $\operatorname{LnR}_{\mathrm{ijk}}=\beta_{\mathrm{K}}+\beta_{1}{ }^{*} \mathrm{~K}_{\mathrm{ijk}}+\beta_{2}{ }^{*}$ Combinations $_{\mathrm{ijk}}+\mathrm{a}_{\mathrm{i}}+\mathrm{b}_{\mathrm{ij}}+\varepsilon_{\mathrm{ijk}}$ & $\begin{array}{l}\text { Records with information on K concerning legume } \\
\text { CCs grown in winter, non-legume CCs grown in } \\
\text { winter, and legume CCs grown in summer }\end{array}$ \\
\hline 9 & Combination & $\operatorname{LnR}_{\mathrm{ijk}}=\beta_{\mathrm{A}}+\beta_{1}{ }^{*}$ Combination $_{\mathrm{ijk}}+\mathrm{a}_{\mathrm{i}}+\mathrm{b}_{\mathrm{ij}}+\varepsilon_{\mathrm{ijk}}$ & $\begin{array}{l}\text { Only for legume CCs grown in winter, non-legume } \\
\text { CCs grown in winter, and legume CCs grown in } \\
\text { summer }\end{array}$ \\
\hline
\end{tabular}




\section{CC type CC season Crop species}

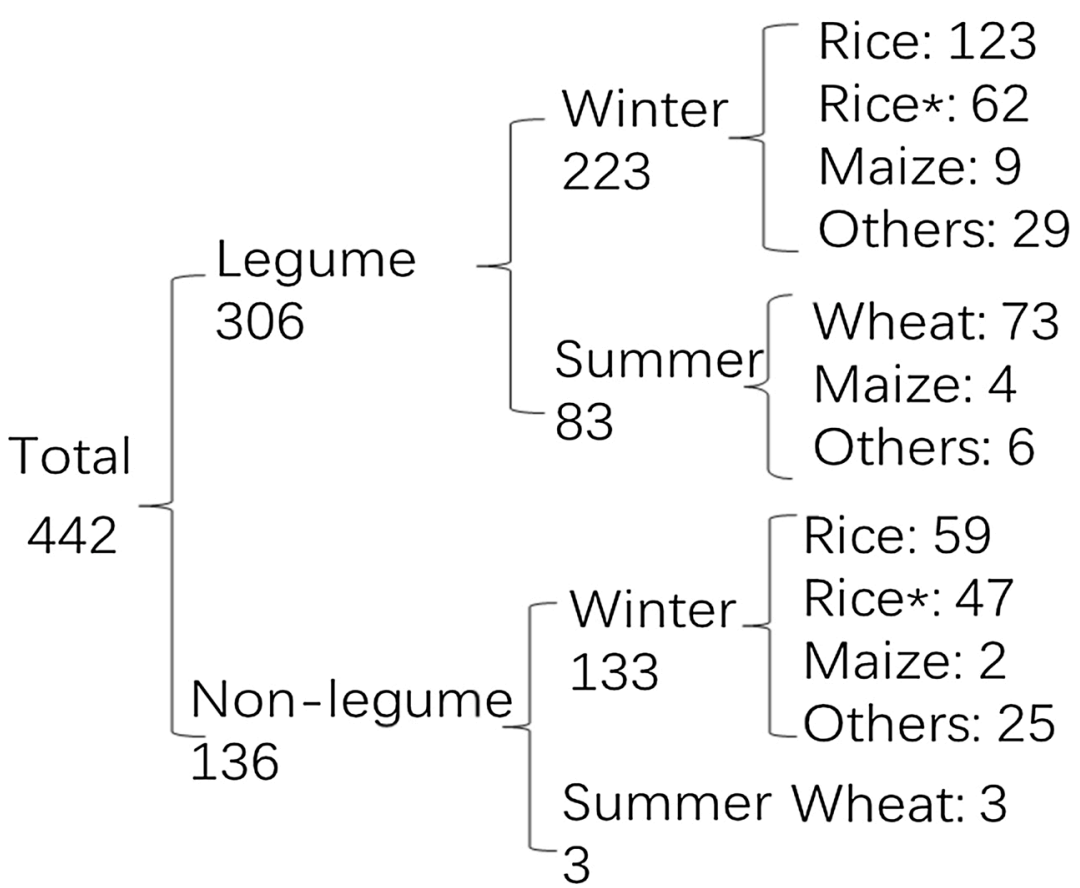

Fig. 1. Structure of the data base used in this study. Of a total of 442 records, 306 represent studies with legume cover crops (CCs) and 136 represent studies with non-legume CCs. Legume CCs were grown both during the winter season (223 records) or the summer season (83 records). For non-legume CCs, almost all records were grown in winter. There were not enough records to analyze performance of non-legume CCs grown in summer. Winter CCs were mostly grown preceding rice, but also maize and other species. Summer CCs were predominantly grown preceding wheat, with insufficient data for other crop species to allow analysis. See also Fig. S2. with all possible combinations of the explanatory variables. The functions dredge() and model.avg() (R package MuMIn; Barton, 2009) were used to rank the resulting set of models according to BIC and calculate overall average predictions based on BIC weights. The set of top models was delineated with a total model weight of 0.95 (Grueber et al., 2011). R packages plotrix, graphics (Lemon, 2016; R Core Team, 2020) were used for data visualization.

\section{Results}

\subsection{Overview of study}

The frequency distributions of LnR based on data from the" Web of Science" and from "CNKI" were similar (Fig. S3). The KolmogorovSmirnov identified no significant difference between the two cumulative probability distributions of the data based on the two databases ( $\mathrm{D}=0.0841, \mathrm{P}=0.5769$ ). Therefore, the two databases were combined. The final dataset included data from a total of 53 publications: 16 from the web of Science and 37 from the CNKI. In total, 442 comparisons (response ratios) were extracted from 173 experiments (sites $\times$ years) across China. The results of the funnel plot for LnR showed no publication bias (Fig. S4).

Most studies were conducted in the subtropical zone of China (34 publications and 129 experiments) while only 19 publications and 44 experiments were originated from the temperate zone of the country (Fig. 2). Both winter legume and non-legume CCs were widely planted in subtropical zone of China (Southern China; Figs. 1 and 2). In temperate zone of China (Northern China), predominantly summer legume CCs were planted due to the continental climate with very cold and dry winter which is less suitable for growing winter CCs. Only a few of winter CCs were observed in Northern China Plain before planting spring maize, cotton and Tobacco (Fig. S2).

About 368 out of 442 values of the $\ln R(83 \%)$ were higher than zero (Fig. 3) while the median, the first and the third quartile of effect size were $0.042,0.104$, and 0.174 , respectively, corresponding to yield increases due to CCs of 4.3, 11.0 and $19.0 \%$. On average, the primary crop yield increased when replacing a fallow period by CCs. The average LnR was 0.092, which means that CCs significantly $(p<0.001)$ increased the primary crop yield by $9.7 \pm 3.7 \%$ across the entire country $(n=442)$.

\subsection{Importance of the explanatory variables}

Climate zone, soil $\mathrm{pH}, \mathrm{CC}$ type, $\mathrm{CC}$ season, crop species and fertilizers $(\mathrm{N}, \mathrm{P}$ and $\mathrm{K}$ ) inputs might affect the effects of CCs on primary crop yield. A multi-variable analysis and model selection with all possible combinations of the above variables were conducted to evaluate the relative importance of explanatory variables. CC type (legume or non-legume) was consistently included in all models, such that the total weight of CC type reached the theoretical maximum value of 1.00 . The second most important variable was the CC season (winter or summer) with a total weight of 0.67 . Likewise, the third most important variable was $\mathrm{N}$ input with a weight of 0.16 (Fig. 4). Calculations were repeated using AIC weights, with similar results (Fig. S5). The top models from model comparison based on BIC and AIC are presented in Tables S1 and S2.

\subsection{Relationships between variables}

The PCA and correlation matrix showed that explanatory variables were not dependent (Figs. 5 and S6). The PCA showed that climatic zone (temperate and subtropical zone), $\mathrm{CC}$ season, soil $\mathrm{pH}$, crop species and LnR were correlated (Fig. 5). The correlation matrix also showed that climatic zone was highly correlated with CC season, soil pH, and LnR ( R $=-0.90,0.76$, and -0.49 , respectively Fig. S6). The relative importance analysis highlighted that CC type and CC season are the two major factors influencing the effects of CCs on crop yield. Here we chose CC season as a predictor to represent other confounded explanatory factors, including climatic zone, soil $\mathrm{pH}$, and crop species). We combined the two factors CC type and CC season and defined three groups (winter legume, winter non-legume and summer legume) while analyzing the crop yield response to those CC sub-groups (Table1, Fig. S2). A fourth group (summer non-legume) had too few observation records (three) to be included in analysis. 


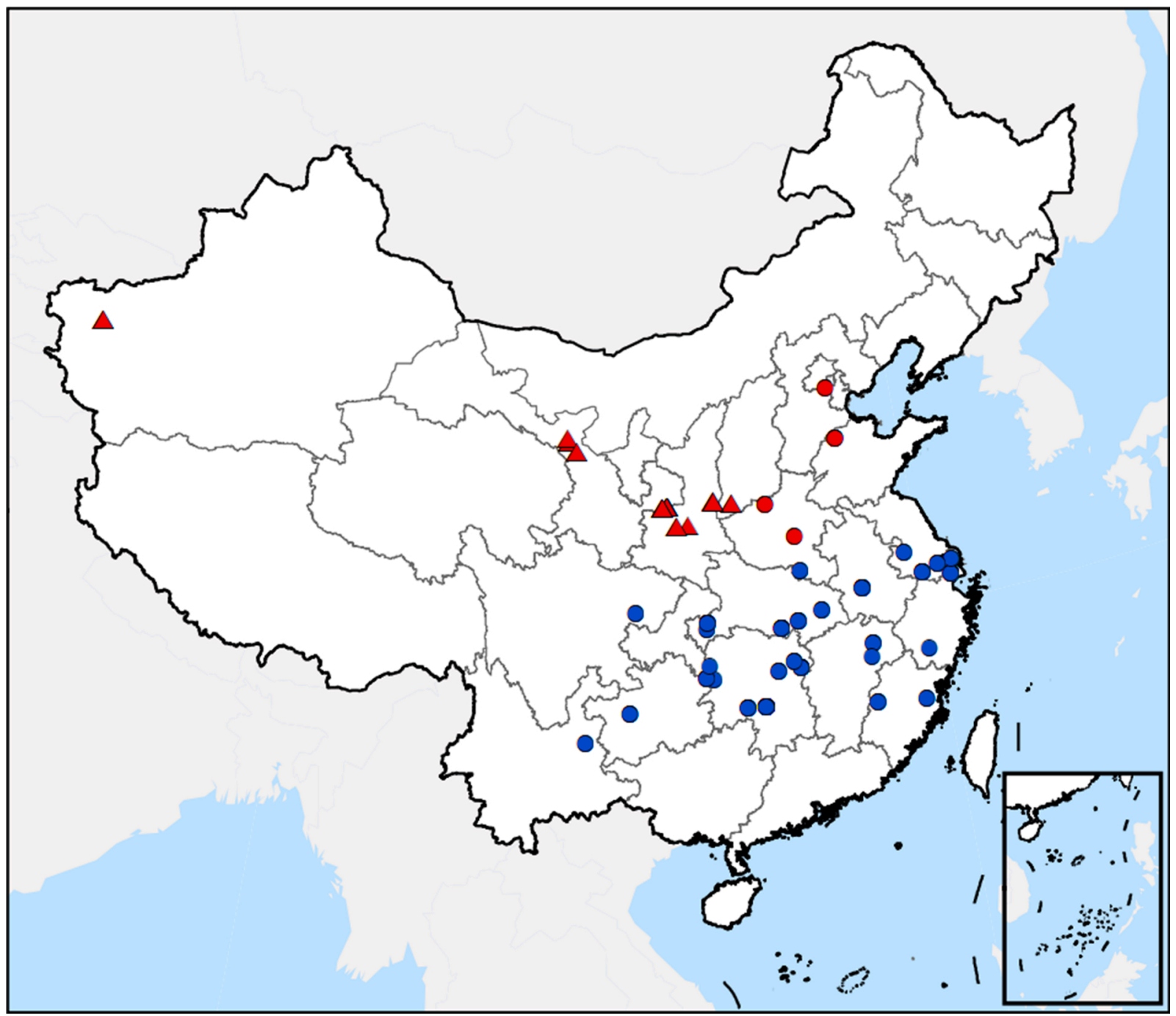

Fig. 2. Overview of cover crop experimental sites considered in the meta-analysis. Red and blue colors represent temperate and subtropical zone while triangles and circles represent cover cropping in summer and winter, respectively. (For interpretation of the references to colour in the Figure, the reader is referred to the web version of this article).

\subsection{Effect of CC sub-groups on main crop yield}

The frequencies of LnR showed differences between CC sub-groups (Fig. 6). The LnR were $97 \%$ (211 out of 218 records) positive in the winter legume sub-group (Fig. 6a), $87 \%$ (116 out of 133 records) positive in the winter non-legume sub-group (Fig. 6b) and $52 \%$ (out 43 of 83 records) positive in the summer legume sub-group (Fig. 6c). The yield benefit of different crop species varied (Fig. 7). Almost all the crop species exhibited significant yield benefit after planting the winter CC (Fig. S7). The yields of rice, rice*, maize and other crops increased by $16.0 \pm 3.0 \%, 19.9 \pm 3.8 \%, 27.2 \pm 9.9 \%$ and $7.9 \pm 6.3 \%$, respectively following winter legume CCs (Fig. 7a). Likewise, the yield of rice, rice* and other crops increased by $10.6 \pm 3.8 \%, 17.1 \pm 4.2 \%$ and $9.7 \pm 5.7$ $\%$, respectively after winter non-legume CCs (Fig. 7b). In contrast, summer legume CCs did not increase any of the main crop yield (Fig. $7 \mathrm{c}$ ).

\subsection{Effects of fertilizers applications}

The yield benefits due to CCs decreased significantly with higher $\mathrm{N}$ input, but not with higher $\mathrm{P}$ and $\mathrm{K}$ fertilizer inputs (Fig. $8 \mathrm{a}, p<0.001$, Fig. $8 \mathrm{~b}, p=0.221$, Fig. $8 \mathrm{c}, p=0.065$ ). The same trends of $\mathrm{N}$ input were found under different CC sub-groups (winter legume, winter nonlegume, and summer legume Fig. 8a, slope $=0.00307$ ). However, the effect of winter legume CCs on crop yield was consistently larger than that of winter non-legume CCs and summer legume CCs (Fig. 8a). The effect of CCs on primary crop yield decreased when $\mathrm{N}$ fertilizer increased from $0 \mathrm{~kg} / \mathrm{ha}$ to $100 \mathrm{~N} \mathrm{~kg}$ /ha: from $23.0-18.5 \%$ with winter legume CCs, from 14.0-9.6\% with winter non-legume CCs, and from 8.6 to 4.6 $\%$ with summer legume CCs (Fig. 8a).

\section{Discussion}

\subsection{Influence of different variables}

Our study confirms that benefits of CCs on primary crop yield varied from one region to another (Figs. 5 and S7). Shackelford et al. (2017) and Alvarez et al. (2017) reported that CCs had, on average, no significant effect on grain yield in California and the Mediterranean and in South America, respectively. However, in the Nordic countries, the negative effects of CCs on grain yield were reported (Valkama et al., 2015). Our study, for the first time, shows that CCs significantly increase crop yield by ca. $10 \%$ across the entire China. This increase in crop yield is higher than that reported from other regional (Alvarez et al., 2017; Shackelford et al., 2019) or global scale (Osipitan et al., 2018; Abdalla et al., 2019; Jian et al., 2020b). Indeed, several studies reported neutral or negative effects of CCs on crop yield (Valkama et al., 2015; Abdalla 


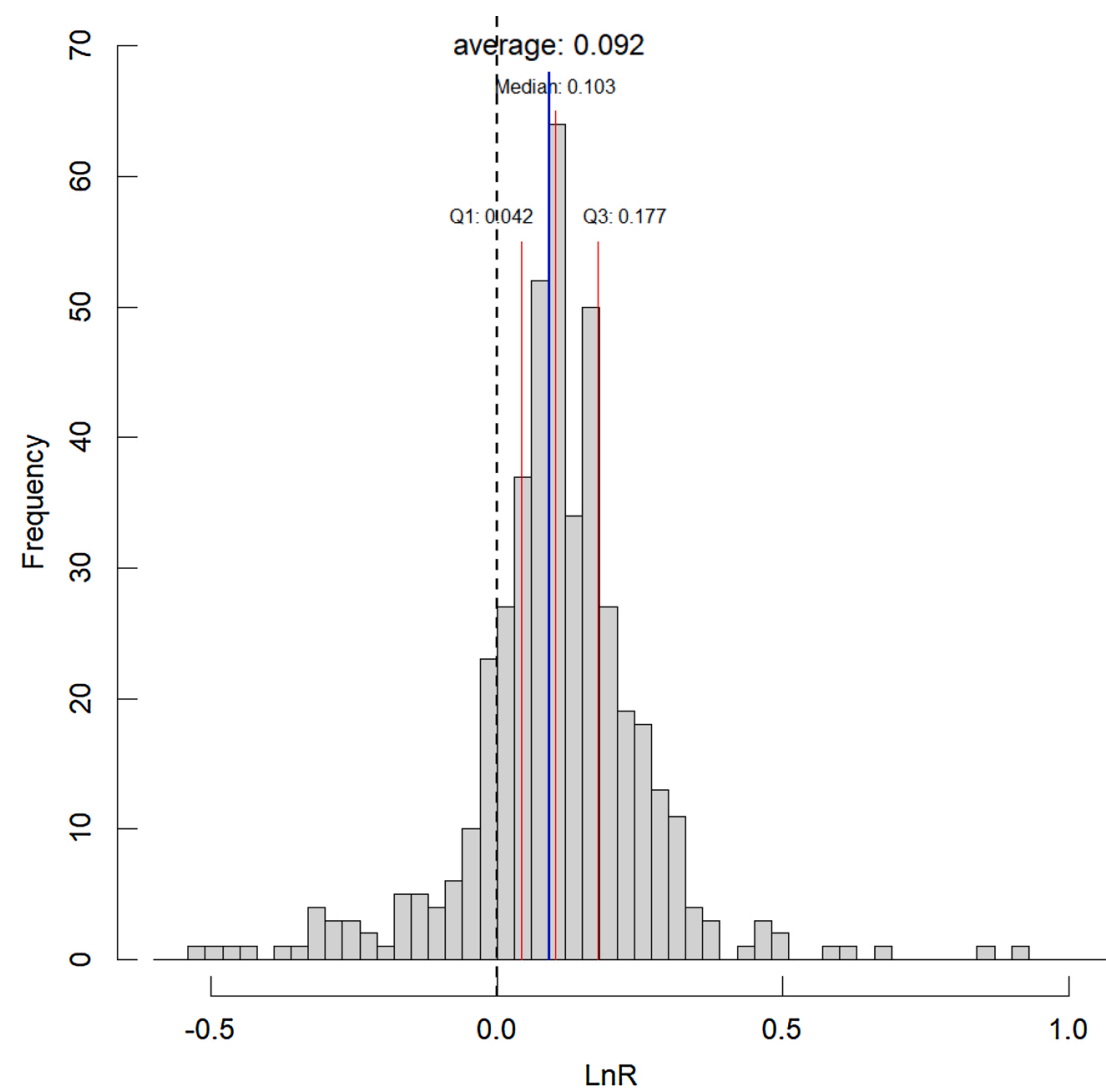

Fig. 3. Frequency distribution of the log response ratio of crop yield with and without preceding cover crop (LnR). Red vertical lines indicate the first quartile (Q1), median and the third (Q3) quartile of LnR. Blue vertical line indicates average LnR. (For interpretation of the references to colour in the Figure, the reader is referred to the web version of this article).

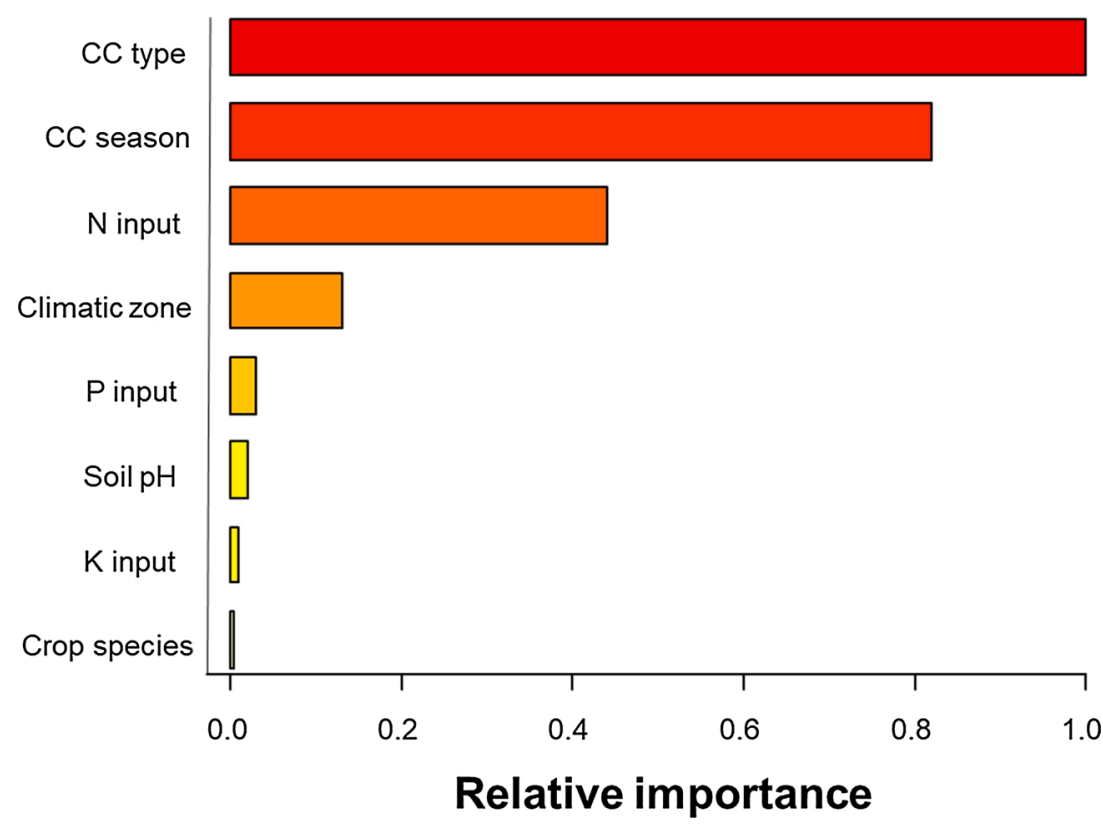

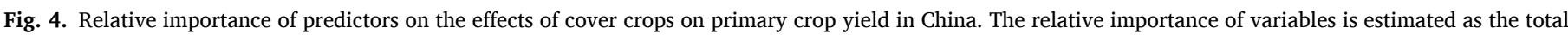

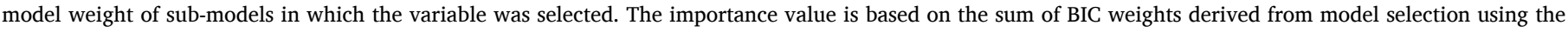
corrected Bayesian information criterion.

et al., 2019; Shackelford et al., 2019; Jian et al., 2020b). The difference between our and previous findings could be related to the different purposes of growing CCs. In China, maintaining or even improving crop production has always been considered as the primary objective of planting CCs to feed the large population with relatively limited arable land. In contrast, enhanced provision of other ecosystem services than that of crop yield has been the key objective of CC-based cropping systems in Europe and North America (Quemada et al., 2013; Basche et al., 


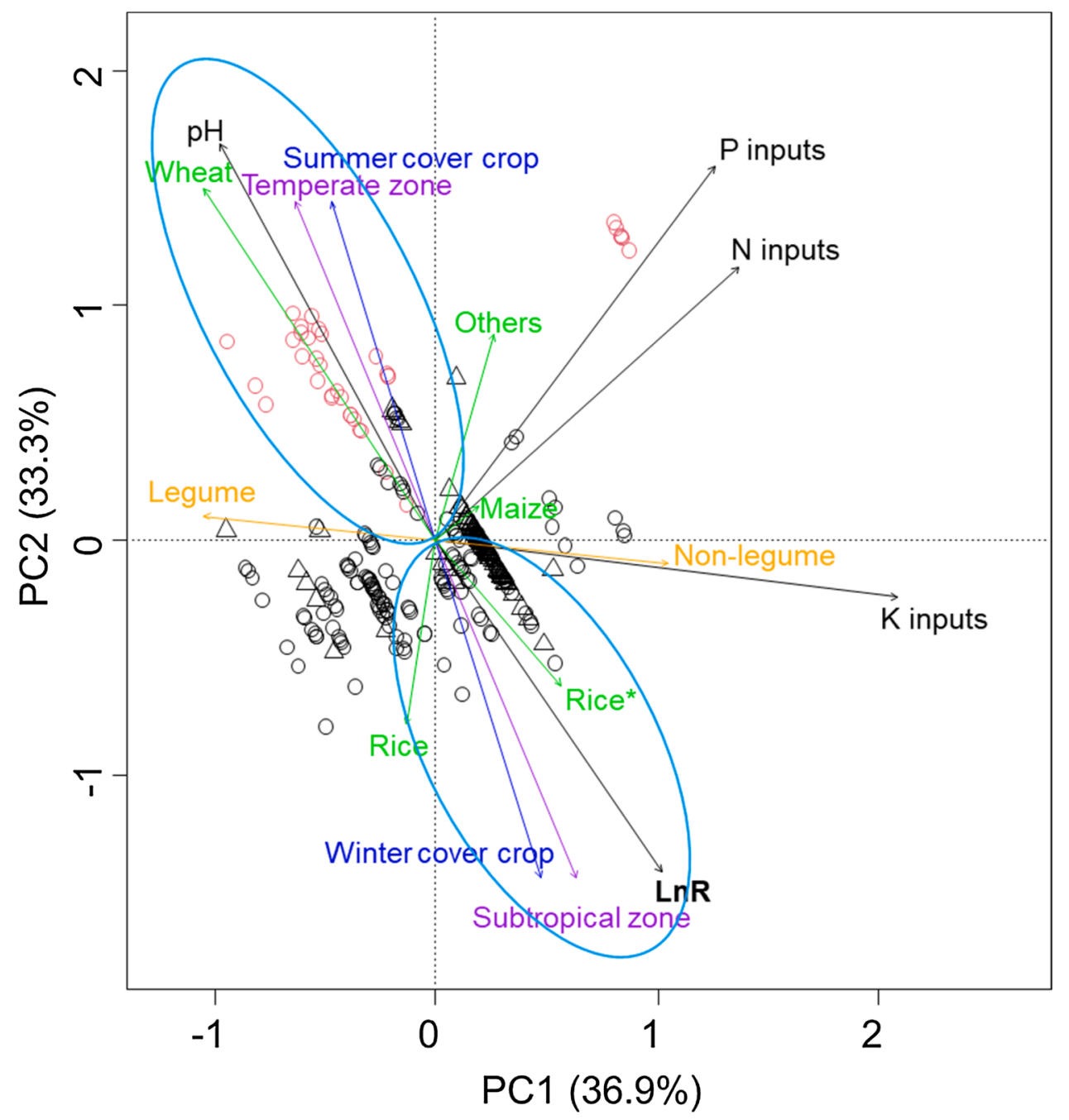

Fig. 5. Principal component analysis of the key explanatory variables and response variable (LnR) based on 319 complete cases originating from 30 studies. The red and black circles represent legume cover crops (CCs) grown in summer and winter, respectively while the black triangles indicate non-legume CCs grown in winter. The black and colored arrows represent continuous and categorical variables, respectively. Rice represents first season rice while Rice* indicates second season rice. (For interpretation of the references to colour in the Figure, the reader is referred to the web version of this article).
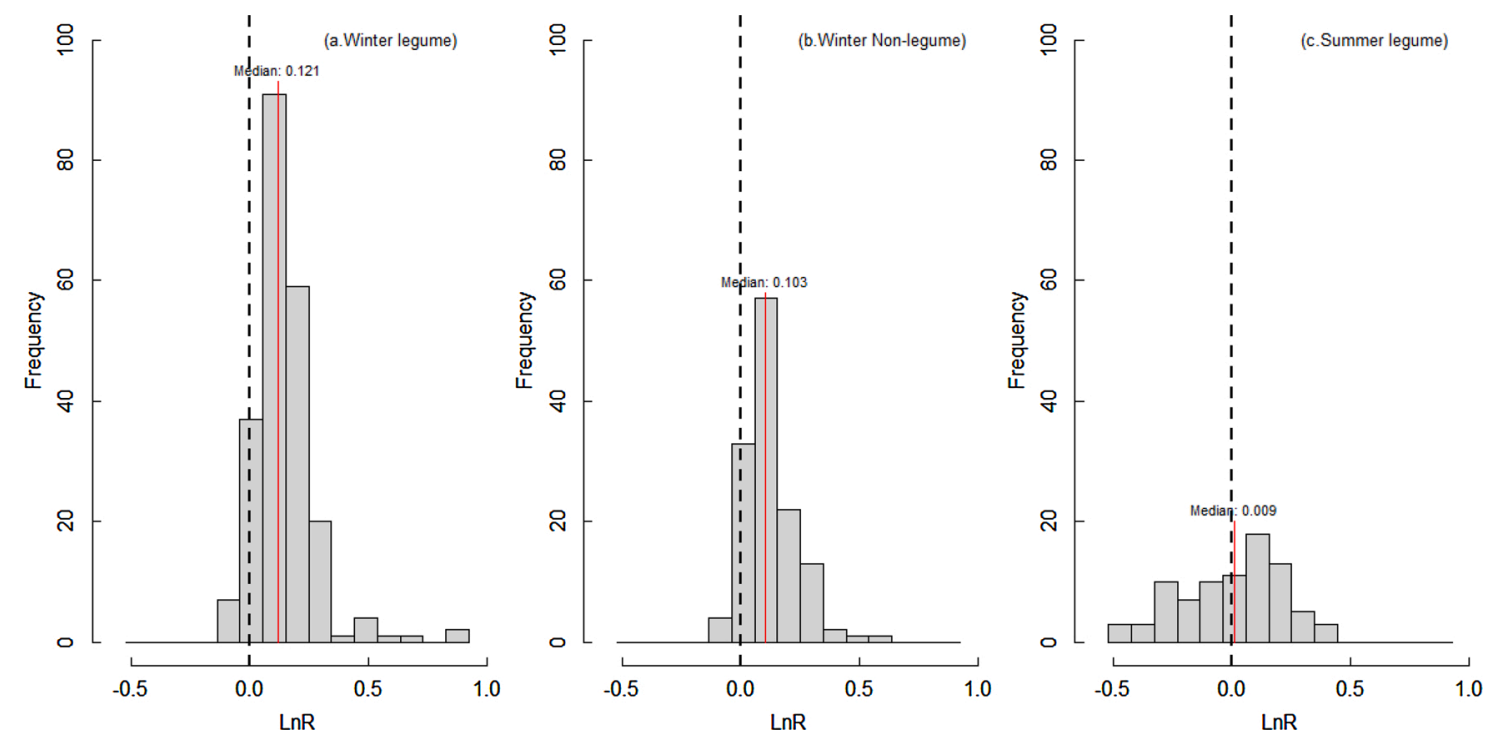

Fig. 6. Frequency distribution of response variable (LnR) of three different cover crops (CCs) sub-groups (a: legume CCs grown in winter; b: non-legume CCs grown in winter; c: legume CCs grown in summer). Red vertical lines in each panel indicate the median LnR. The dashed line represents an LnR of zero, i.e. no yield difference with or without CCs. (For interpretation of the references to colour in the Figure, the reader is referred to the web version of this article). 

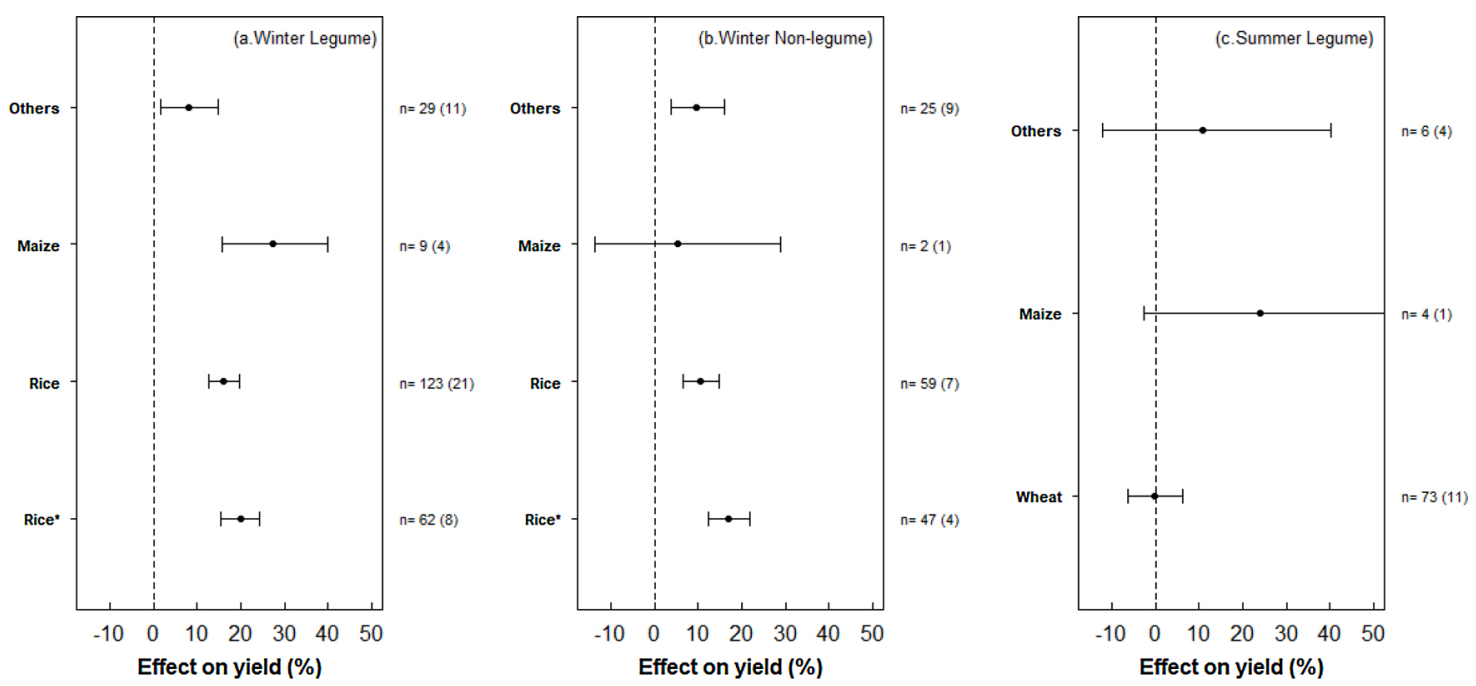

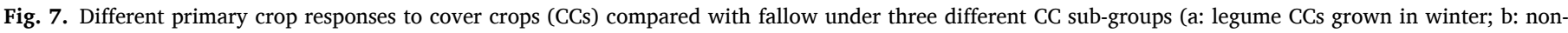

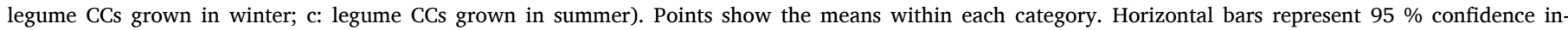

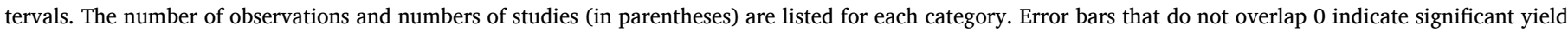
increase due to cover cropping at $\mathrm{p}<0.05$.
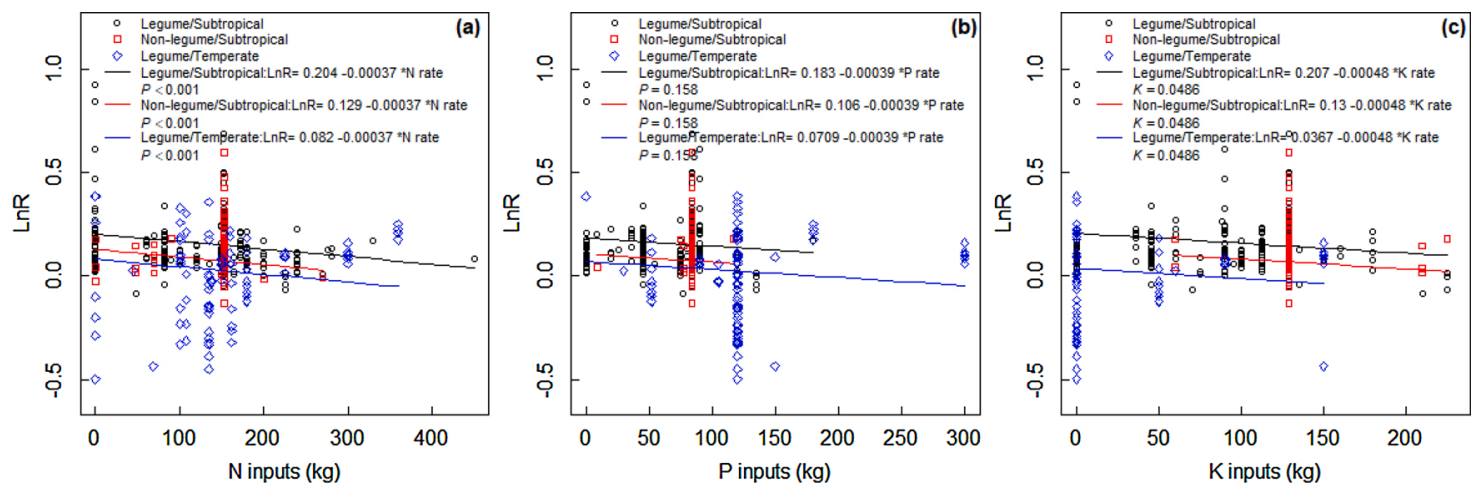

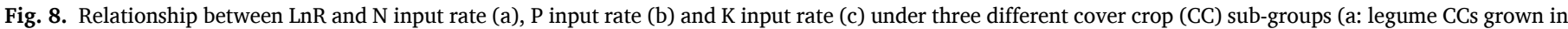
winter; b: non-legume CCs grown in winter; c: legume CCs grown in summer), $P$-value is related to the slopes of the regression.

\section{4; Wortman, 2016; Mahal et al., 2018; Shackelford et al., 2019).}

Our study identified CC type, CC season and N input as the most important variables affecting subsequent crop yields (Fig. 4). Legume CCs as a pre-crop increased first season rice yield by $16.0 \pm 3.0 \%$ while non-legume CCs increased first season rice yield by $10.6 \pm 3.8 \%$ (Fig. $7 \mathrm{a}$ and b). The greater effect of legume CCs may be due to an increased $\mathrm{N}$ input provided in the cropping system via biological $\mathrm{N}$-fixation and $\mathrm{N}$ rich residues (Thorup-Kristensen et al., 2003; Gao et al., 2018). This finding is consistent with earlier studies. Quemada et al. (2013); Thapa et al. (2018), and Shackelford et al. (2019) reported that primary crop yield in agro-systems with legume CCs was significantly greater than primary crop yield in systems with non-legume CCs, globally. According to the literature, primary crop yield was always increased with legume CCs (Quemada et al., 2013; Valkama et al., 2015; Marcillo and Miguez, 2017; Shackelford et al., 2019), but not always with non-legume CCs. Quemada et al. (2013); Marcillo and Miguez (2017); Tonitto et al. (2006), and Alvarez et al. (2017) reported a neutral effect of non-legume CCs on primary crops yields, while Valkama et al. (2015) and Shackelford et al. (2019) demonstrated significant negative effect of these CCs on subsequent crop yield. Our meta-analysis found the positive effects of legume CCs and non-legume CCs on primary crop yield in subtropical zone, but neutral effects in temperate zone (Fig. 7). The differences between our study and previous studies might be due to climatic and environmental conditions. Non-legume CCs require higher soil moisture and nutrients than legumes, which results in relatively lower soil moisture and nutrients for succeeding crops leading to negative effects on primary crop yield in drier areas (Dabney et al., 2001; Alvarez et al., 2017). Here we showed that non-legume CCs were mainly planted in subtropical zone of China, where a high MAT and MAP would not restrict rice growth, due to sufficient water and heat resources (Cherr et al., 2006). Our study also found that effect of both legume and non-legume CCs on yield of the second season rice $(19.9 \pm 3.8 \%$, $17.1 \pm 4.2 \%$, respectively) were higher than that of the first season rice $(16.0 \pm 3.0 \%, 10.6 \pm 3.8 \%$, respectively) (Fig. $7 \mathrm{a}$ and b). This may especially occur as most of the nutrients from CC were organically bounded and that the $\mathrm{CC}$ decomposition rate of the first season rice was slower than that of the second season rice, due to higher MAP and MAT in the latter rice growth period (Yao et al., 2017; Raheem et al., 2019).

The CC season was another important variable influencing primary crop yield (Fig. 5). In this study, two important different CC-based cropping systems have been identified in China and they are associated with two types of environmental conditions (Fig. 5). The first regards the rice system associated with winter CCs, mainly distributed in the subtropical zones of China, with high MAT, MAP and low soil $\mathrm{pH}$ (Fig. S8). The effects of winter CCs on yield of first and second season rice were positive (Fig. 5). The second concerns the wheat-based system with summer CCs, distributed in temperate zones of China, with relatively low MAT, MAP but high soil pH (Fig. S8). No significant benefit of 
growing CCs was found in this system (Fig. 5). Winter CCs planted in subtropical zones with higher values of MAP and MAT would not restrict rice growth due to sufficient water and heat resources (Cherr et al., 2006). Furthermore, higher values of MAT in the subtropical zone may improve soil microbial activity with higher rates of CC residue decomposition and nutrient turn over, which finally improve soil nutrient availability for the following primary crop growth (Varela et al., 2014; Hallama et al., 2018). Besides, winter CCs could improve the content of water-stable aggregates in the plow layer soil, which would have a positive effect on the subsequent crop yield (Basche and DeLonge, 2017; Jian et al., 2020b). However, summer CCs were only planted in temperate region with lower values of MAP and MAT in China, whereby summer CCs would have consumed water. This results in a more constrained water resource for the subsequent wheat growth, and consequently, decreased wheat yield by lower number of wheat tillers compared with fallow (Dabin et al., 2015). Furthermore, lower MAT values in temperate zone of China may limit mineralization of CC residues without any yield benefits of the subsequent crop (Schroth et al., 2001).

Overall, we found that $\mathrm{N}$ input was negatively related to the positive yield effect of cover cropping on the subsequent crop (Fig. 8a) as shown previously (Valkama et al., 2015; Marcillo and Miguez, 2017). The yield gap between growing CC (winter legume CC, winter non-legumes CC, and summer legume $\mathrm{CC}$ ) and control is more pronounced at lower $\mathrm{N}$ rates and narrows with increasing $\mathrm{N}$ input. This could be explained by a relatively higher mineralization of CCs residues at lower fertilizer application rates compared with that occurring at higher fertilizer application rates. With more $\mathrm{N}$ input, crop uptakes fertilizer $\mathrm{N}$ as a priority. However, with lower $\mathrm{N}$ input, $\mathrm{N}$ capture in winter and mineralization during summer is more important for crop performance.

Our study showed that legume CCs field experiments have been widely tested in the subtropical and temperate zone of China and that the observations of legume CC account for ca. $70 \%$ of the total observations (i.e. 442) in China. This proportion is significantly higher than that reported from other countries or regions of the world (Valkama et al., 2015; Abdalla et al., 2019; Shackelford et al., 2019; Jian et al., 2020a). This can also explain that the overall potential of CCs on crop yield in China is higher than that reported from other regional or global scale.

\subsection{Limitations and perspectives}

This study only focused on the effect of CCs on crop yield, which was the main purpose of planting CCs in China. However, crop yield is one out of multiple ecosystems services provided by CCs (Schipanski et al., 2014). How CCs affect the nutrients enrichment (especially N leaching) and other ecosystem services are still unknown in China. Previous studies reported the need to find a trade-off between crop yield and other ecosystem services provided by CCs (Abdalla et al., 2019; Shackelford et al., 2019). However, whether these trade-offs exist in China or not are still unknown. Further analysis of including multiple ecosystem services provided by CCs is needed to shed light in this regard.

Our study showed an average primary crop yield increase associated with CCs in China. This means that farmer can increase their gross income by introducing CCs into their cropping systems. However, whether there is a higher benefit-cost ratio due to CC is still unknown as only a few studies conducted to date reported the cost of growing CC in China. The economic value of ecosystem services provided by CC should be an important future research topic that will facilitate the decision-making process aimed at sustainable agroecosystem management.

While a range of variables affecting the potential of CC on primary crop yield have been identified in this study, additional factors related to CCs might also affect primary crop yield, which were not considered here due to the limited data availability. These factors may include soil structure (Valkama et al., 2015; Toler et al., 2019), CC termination time (Marcillo and Miguez, 2017), the type of seedbed preparation (conventional or conservation tillage) (Pittelkow et al., 2015a, b; Behnke et al., 2020), and single or mixture CC species (Shackelford et al., 2019). Future studies should fill this knowledge gap.

Our study showed that some of the factors among the investigated predictor variables do not influence the effect size independently. CC growing season, climate zone, soil $\mathrm{pH}$ and crop species were correlated variables and their effects are not easily separated. Simple statistical methods (e.g. meta-regression analysis) could not identify the relationships between those variables. Multiple methods (including PCA, relative importance, and correlation analysis) are useful tools to analyse the confounded effects and make the meta-regression analysis more robust. Combining meta-regression and other statistical methods is, therefore, highly recommended for future meta-analysis studies.

\section{Conclusions}

This study represents a first attempt to quantify the effects of CCs on crop yield in China. We showed that there is a great crop yield increase (Ca. $10 \%$ ) potential of growing CCs in the country compared with fallow with an important contribution to food security.

Long-term over use of chemical fertilizers has accelerated the soil acidification in China (Guo et al., 2010; Zeng et al., 2017). Ca. $37 \%$ of paddy soil has been degraded to some extent in the last decade (NSB). With the strict regulation governing "Zero-Growth Action on systematic fertilizer" in China, the ability of CC to supply $\mathrm{N}$ and increase main crop yield might become more attractive to farmers in the coming years. Our study shows that CCs might be a useful option to replace or minimize the use of chemical fertilizers in the paddy soil, and, at the same time, protect the environment. Policy makers are thus encouraged to extend the GMPP policy to the subtropical zone, characterized by paddy fields. Introducing winter legume CCs in subtropical zone is highly recommendable for farmers to increase rice yield. However, due to no significant beneficial effect on yield, summer CC introduction is not advisable for wheat-based cropping system in the temperate zone due to the lower rainfall and the possibility of competition for scarce water resources between cover crops and main crops.

\section{Declaration of Competing Interest}

This material has not been published elsewhere and has not been submitted simultaneously for publication elsewhere.

We hope this manuscript will be found suitable for Field Crops Research.

\section{Acknowledgments}

We thank John R. Porter, Wenli Ding, Ji Chen, Zhan Xu and Shingirai Mudare for their helpful comments. Thanks also give to the anonymous revivers for their helpful comments. This work is supported by the National Natural Science Foundation of China (Grant No. 31800379, 32072676), Key Consulting Project of the Chinese Academy of Engineering (2019-XZ-69), and China Postdoctoral Science Foundation (Grant No. 2019M660866).

\section{Appendix A. Supplementary data}

Supplementary material related to this article can be found, in the online version, at doi:https://doi.org/10.1016/j.fcr.2021.108237.

\section{References}

Abdalla, M., Hastings, A., Cheng, K., Yue, Q., Chadwick, D., Espenberg, M., Truu, J., Rees, R.M., Smith, P., 2019. A critical review of the impacts of cover crops on nitrogen leaching, net greenhouse gas balance and crop productivity. Glob. Chang. Biol. 25, 2530-2543. 
Alexander, R.B., Smith, R.A., Schwarz, G.E., Boyer, E.W., Nolan, J.V., Brakebill, J.W., 2008. Differences in phosphorus and nitrogen delivery to the Gulf of Mexico from the Mississippi River Basin. Environ. Sci. Technol. 42, 822-830.

Alvarez, R., Steinbach, H.S., De Paepe, J.L., 2017. Cover crop effects on soils and subsequent crops in the pampas: a meta-analysis. Soil Tillage Res. 170, 53-65.

Barton, K., 2009. MuMIn: Multi-model Inference, R Package Version 0.12.0. http: //r-forge.r-project.org/projects/mumin/.

Basche, A., DeLonge, M., 2017. The impact of continuous living cover on soil hydrologic properties: a meta-analysis. Soil Sci. Soc. Am. J. 81, 1179.

Basche, A.D., Miguez, F.E., Kaspar, T.C., Castellano, M.J., 2014. Do cover crops increase or decrease nitrous oxide emissions? A meta-analysis. J. Soil Water Conserv. 69, $471-482$.

Behnke, G.D., Kim, N., Villamil, M.B., 2020. Agronomic assessment of cover cropping and tillage practices across environments. Agron. J. 112, 3913-3928.

Bennett, A.J., Bending, G.D., Chandler, D., Hilton, S., Mills, P., 2012. Meeting the demand for crop production: the challenge of yield decline in crops grown in short rotations. Biol. Rev. 87, 52-71.

Bergtold, J.S., Ramsey, S., Maddy, L., Williams, J.R., 2019. A review of economic considerations for cover crops as a conservation practice. Renew. Agric. Food Syst. $34,62-76$.

Blesh, J., Drinkwater, L., 2013. The impact of nitrogen source and crop rotation on nitrogen mass balances in the Mississippi River Basin. Ecol. Appl. 23, 1017-1035.

Cao, W., Bao, X., Xu, C., Nie, J., Gao, Y., Geng, M.-j., 2017. Reviews and prospects on science and technology of green manure in China. J. Plant Nutr. Fert. 23, 1450-1461.

Cherr, C.M., Scholberg, J.M.S., McSorley, R., 2006. Green manure approaches to crop production: a synthesis. Agron. J. 98, 302-319.

Dabin, Z., Pengwei, Y., Na, Z., Zheng, W., Changwei, Y., Qunhu, C., Weidong, C., Yajun, G., 2015. Responses of winter wheat production to green manure and nitrogen fertilizer on the Loess Plateau. Agron. J. 107, 361.

Dabney, S.M., Delgado, J.A., Reeves, D.W., 2001. Using winter cover crops to improve soil and water quality. Commun. Soil Sci. Plant Anal. 32, 1221-1250.

Edgerton, M.D., 2009. Increasing crop productivity to meet global needs for feed, food, and fuel. Plant Physiol. 149, 7-13.

Gao, S.-j., Gao, J.-s., Cao, W.-d., Zou, C.-q., Huang, J., Bai, J.-s., Dou, F.-g., 2018. Effects of long-term green manure application on the content and structure of dissolved organic matter in red paddy soil. J. Integr. Agric. 17, 1852-1860.

Gong, P., Liang, L., Zhang, Q., 2011. China must reduce fertilizer use too. Nature 473, 284-285.

Grueber, C.E., Nakagawa, S., Laws, R.J., Jamieson, I.G., 2011. Multimodel inference in ecology and evolution: challenges and solutions. J. Evol. Biol. 24, 699-711.

Guo, J.H., Liu, X.J., Zhang, Y., Shen, J.L., Han, W.X., Zhang, W.F., Christie, P., Goulding, K.W.T., Vitousek, P.M., Zhang, F.S., 2010. Significant acidification in major chinese croplands. Science 327, 1008-1010.

Hallama, M., Pekrun, C., Lambers, H., Kandeler, E., 2018. Hidden miners - the roles of cover crops and soil microorganisms in phosphorus cycling through agroecosystems. Plant Soil 434, 7-45.

Hedges, L.V., Gurevitch, J., Curtis, P.S., 1999. The meta-analysis of response ratios in experimental ecology. Ecology 80, 1150-1156.

Jian, J., Du, X., Reiter, M.S., Stewart, R.D., 2020a. A meta-analysis of global cropland soil carbon changes due to cover cropping. Soil Biol. Biochem. 143, 107735.

Jian, J., Lester, B.J., Du, X., Reiter, M.S., Stewart, R.D., 2020b. A calculator to quantify cover crop effects on soil health and productivity. Soil Tillage Res. 199, 104575.

Kaye, J.P., Quemada, M., 2017. Using cover crops to mitigate and adapt to climate change. A review. Agron. Sustain. Dev. 37.

Koricheva, J., Gurevitch, Jessica, Mengersen, Kerrie, 2013. Handbook of Meta-analysis in Ecology and Evolution. Princeton University Press.

Larkin, R.P., Griffin, T.S., Honeycutt, C.W., 2010. Rotation and cover crop effects on soilborne potato diseases, tuber yield, and soil microbial communities. Plant Dis. 94, 1491-1502.

Lemon, J., 2016. Plotrix: a package in the red light district of R. R-news 6, 8-12.

Li, Q., 1999. Science and Technology Methodology. Dictionary Science press, Beijing, China.

Li, C., Hoffland, E., Kuyper, T.W., Yu, Y., Zhang, C., Li, H., Zhang, F., van der Werf, W. 2020a. Syndromes of production in intercropping impact yield gains. Nat. Plants.

Li, F., Ren, J., Wimmer, S., Yin, C., Li, Z., Xu, C., 2020b. Incentive mechanism for promoting farmers to plant green manure in China. J. Clean. Prod. 267, 122197.

Liu, X.J., Zhang, Y., Han, W.X., Tang, A.H., Shen, J.L., Cui, Z.L., Vitousek, P., Erisman, J. W., Goulding, K., Christie, P., Fangmeier, A., Zhang, F.S., 2013. Enhanced nitrogen deposition over China. Nature 494, 459-462.

Mahal, N.K., Castellano, M.J., Miguez, F.E., 2018. Conservation agriculture practices increase potentially mineralizable nitrogen: a meta-analysis. Soil Sci. Soc. Am. J. 82 1270.

Makowski, D., Piraux, F., Brun, F., 2019. From Experimental Network to Meta-analysis. Springer, Netherlands.

MARA, 2015. Ministry of Agriculture and Rural Affairs of the People's Republic of China Available online: www.moa.gov.cn/nybgb/ (accessed on 23. December 2020).

Marcillo, G.S., Miguez, F.E., 2017. Corn yield response to winter cover crops: an updated meta-analysis. J. Soil Water Conserv. 72, 226-239.

Martin-Guay, M.O., Paquette, A., Dupras, J., Rivest, D., 2018. The new Green Revolution: sustainable intensification of agriculture by intercropping. Sci. Total Environ. 615, 767-772.

McDaniel, M.D., Tiemann, L.K., Grandy, A.S., 2014. Does agricultural crop diversity enhance soil microbial biomass and organic matter dynamics? A meta-analysis. Ecol. Appl. 24, 560-570.
Oksanen, J., Blanchet, F.G., Friendly, M., Kindt, R., McGlinn, D., Minchin, P.R., O'Hara, R.B., Simpson, G.L., Solymos, P., Stevens, M.H.H., Szoecs, E., Wagner, H., 2019. Package 'vegan'. Community Ecology Package, Version R Package Version 2.5-6. https://CRAN.R-project.org/package=vegan.

Osipitan, O.A., Dille, J.A., Assefa, Y., Knezevic, S.Z., 2018. Cover crop for early season weed suppression in crops: systematic review and meta-analysis. Agron. J. 110, 2211-2221.

Philibert, A., Loyce, C., Makowski, D., 2012. Assessment of the quality of meta-analysis in agronomy. Agric. Ecosyst. Environ. 148, 72-82.

Pinheiro, J.C., Bates, D.J., Debroy, S.D., Sakar, D., 2009. Nlme: linear and nonlinear mixed effects models. R package version 3, 1-117.

Pittelkow, C.M., Liang, X., Linquist, B.A., van Groenigen, K.J., Lee, J., Lundy, M.E., van Gestel, N., Six, J., Venterea, R.T., van Kessel, C., 2015a. Productivity limits and potentials of the principles of conservation agriculture. Nature 517, 365-368.

Pittelkow, C.M., Linquist, B.A., Lundy, M.E., Liang, X., van Groenigen, K.J., Lee, J., van Gestel, N., Six, J., Venterea, R.T., van Kessel, C., 2015b. When does no-till yield more? A global meta-analysis. Field Crops Res. 183, 156-168.

Poeplau, C., Don, A., 2015. Carbon sequestration in agricultural soils via cultivation of cover crops - a meta-analysis. Agric. Ecosyst. Environ. 200, 33-41.

Quemada, M., Baranski, M., Nobel-de Lange, M.N.J., Vallejo, A., Cooper, J.M., 2013. Meta-analysis of strategies to control nitrate leaching in irrigated agricultural systems and their effects on crop yield. Agric. Ecosyst. Environ. 174, 1-10.

R Core Team, 2020. R: a Language and Environment for Statistical Computing. R Foundation for Statistical Computing., Vienna, Austria.

Raheem, A., Zhang, J., Huang, J., Jiane, Y., Siddik, M.A., Denga, A.X., Gao, J.S., Zhang, W.J., 2019. Greenhouse gas emissions from a rice-rice-green manure cropping system in South China. Geoderma 353, 331-339.

Repullo-Ruibérriz de Torres, M.A., Ordóñez-Fernández, R., Giráldez, J.V., MárquezGarcía, J., Laguna, A., Carbonell-Bojollo, R., 2018. Efficiency of four different seeded plants and native vegetation as cover crops in the control of soil and carbon losses by water erosion in olive orchards. Land Degrad. Dev. 29, 2278-2290.

Schipanski, M.E., Barbercheck, M., Douglas, M.R., Finney, D.M., Haider, K., Kaye, J.P., Kemanian, A.R., Mortensen, D.A., Ryan, M.R., Tooker, J., White, C., 2014. A framework for evaluating ecosystem services provided by cover crops in agroecosystems. Agric. Syst. 125, 12-22.

Schroth, G., Salazar, E., Da Silva, J.P., 2001. Soil nitrogen mineralization under tree crops and a legume cover crop in multi-strata agroforestry in central Amazonia: spatial and temporal patterns. Exp. Agric. 37, 253-267.

Seufert, V., Ramankutty, N., Foley, J.A., 2012. Comparing the yields of organic and conventional agriculture. Nature 485, 229-232.

Shackelford, G., Kelsey, R., Robertson, R., Williams, D., Dicks, L., 2017. Sustainable Agriculture in California and Mediterranean Climates: Evidence for the Effects of Selected Interventions. University of Cambridge, Cambridge.

Shackelford, G.E., Kelsey, R., Dicks, L.V., 2019. Effects of cover crops on multiple ecosystem services: ten meta-analyses of data from arable farmland in California and the Mediterranean. Land Use Policy 88, 104204.

Sileshi, G., Akinnifesi, F.K., Ajayi, O.C., Place, F., 2008. Meta-analysis of maize yield response to woody and herbaceous legumes in sub-Saharan Africa. Plant Soil 307, $1-19$.

Thapa, R., Mirsky, S.B., Tully, K.L., 2018. Cover crops reduce nitrate leaching in agroecosystems: a global meta-analysis. J. Environ. Qual. 47, 1400-1411.

Thorup-Kristensen, K., Magid, J., Jensen, L.S., 2003. Catch crops and green manures as biological tools in nitrogen management in temperate zones. Advances in Agronomy 79 (79), 227-302.

Tilman, D., Cassman, K.G., Matson, P.A., Naylor, R., Polasky, S., 2002. Agricultural sustainability and intensive production practices. Nature 418, 671-677.

Toler, H.D., Augé, R.M., Benelli, V., Allen, F.L., Ashworth, A.J., 2019. Global metaanalysis of cotton yield and weed suppression from cover crops. Crop Sci. 59, 1248-1261.

Tonitto, C., David, M.B., Drinkwater, L.E., 2006. Replacing bare fallows with cover crops in fertilizer-intensive cropping systems: a meta-analysis of crop yield and $\mathrm{N}$ dynamics. Agric. Ecosyst. Environ. 112, 58-72.

Valkama, E., Lemola, R., Känkänen, H., Turtola, E., 2015. Meta-analysis of the effects of undersown catch crops on nitrogen leaching loss and grain yields in the Nordic countries. Agric. Ecosyst. Environ. 203, 93-101.

Varela, M.F., Scianca, C.M., Taboada, M.A., Rubio, G., 2014. Cover crop effects on soybean residue decomposition and P release in no-tillage systems of Argentina. Soil Tillage Res. 143, 59-66.

Vogelweith, F., Thiéry, D., 2017. Cover crop differentially affects arthropods, but not diseases, occurring on grape leaves in vineyards. Aust. J. Grape Wine Res. 23 426-431.

Wang, Y., Dong, H., Zhu, Z., Gerber, P.J., Xin, H., Smith, P., Opio, C., Steinfeld, H., Chadwick, D., 2017. Mitigating greenhouse gas and Ammonia emissions from swine manure management: a system analysis. Environ. Sci. Technol. 51, 4503-4511.

Wei, T., Simko, V., 2017. R Package 'corrplot'. Visualization of a Correlation Matrix (Version 0.84). Available from. https://github.com/taiyun/corrplot.

Wortman, S.E., 2016. Weedy fallow as an alternative strategy for reducing nitrogen loss from annual cropping systems. Agron. Sustain. Dev. 36.

Yao, Y.L., Zhang, M., Tian, Y.H., Zhao, M., Zhang, B.W., Zhao, M., Zeng, K., Yin, B., 2017. Duckweed (Spirodela polyrhiza) as green manure for increasing yield and reducing nitrogen loss in rice production. Field Crops Res. 214, 273-282. 
Yu, Y., Stomph, T.-J., Makowski, D., van der Werf, W., 2015. Temporal niche differentiation increases the land equivalent ratio of annual intercrops: a metaanalysis. Field Crops Res. 184, 133-144.
Zeng, M., de Vries, W., Bonten, L.T., Zhu, Q., Hao, T., Liu, X., Xu, M., Shi, X., Zhang, F., Shen, J., 2017. Model-based analysis of the long-term effects of fertilization management on cropland soil acidification. Environ. Sci. Technol. 51, 3843-3851. Zhao, J., Yang, Y., Zhang, K., Jeong, J., Zeng, Z., Zang, H., 2020. Does crop rotation yield more in China? A meta-analysis. Field Crops Res. 245, 107659. 